\title{
NOTAS
}

\section{DOS NOTAS SOBRE NEBRIJA}

\section{NebriJa, INICIAdor DE LA GRAMÁtica MOdERNA}

Como es bien sabido, la Gramática castellana de Nebrija no fue, cronológicamente, la primera que se escribió sobre una lengua vulgar del Occidente europeo. No obstante, las "gramáticas" anteriores a ella no han recibido la atención que por su antigüedad merecen".

Resulta difícil precisar la fecha de composición de las Regole della lingua fiorentina, aunque, de acuerdo con los cálculos de Luigi Morandi², debió escribirse en 1492 o antes. En efecto, aunque el único ejemplar hoy conservado de las Regole (Biblioteca Vaticana) lleva la fecha de 1508, la obra se cita ya en el inventario de la Biblioteca de los Médicis hecho en $1495^{3}$. El nombre del autor no figura en el manuscrito, pero como en 1500 aproximadamente Leonardo da Vinci menciona una gramática escrita por Lorenzo de' Medici, de quien nos consta que era partidario de la lengua vulgar frente a la latina, es probable que Lorenzo el Magnífico sea el autor de estas Regole, y en ese caso la obra debió estar terminada por lo menos en $\mathbf{1 4 9 2}$, año de la muerte del humanista. Las Regole reflejan la lengua hablada en Florencia, y muy brevemente estudian los sonidos, declinaciones, género, pronombres, artículo, conjugaciones, preposiciones, adverbios, interjecciones y conjunciones, y se hace mención de algunos barbarismos.

Más antiguas todavía que estas Regole son tres gramáticas provenzales y una francesa. Las primeras pertenecen a los siglos xiI y xIv: el Donatz proensals de Hugues Faidit (ca. 1240), las Rasos de trobar de Raymond Vidal (ca. 1250) y las Flors del gay saber de Guillaume Molinier (1956). La obra francesa, el Donait françois de Jean Barton, se escribió en 1409 .

Con justa razón señala Lapesa que "estos tratados rudimentarios no se pueden comparar con el de Nebrija, infinitamente superior a ellos

1 Cf. Rafaer LApesa, Historia de la lengua española, $3^{\mathrm{a}}$ ed., Madrid, 1955, p. 190, y Albert Dauzat, Histoire de la langue française, Paris, 1930, p. 18, donde se mencionan las primeras gramáticas provenzales $y$ anglo-francesas. Cf. también Lovis KuKENHEIM, Contributions à l'histoire de la grammaire italienne, espagnole et francaise, Amsterdam, I932, pp. 89 y 95, donde se citan las Regole della lingua fiorentina y las gramáticas provenzales.

2 LUigi Morand, Lorenzo il Magnifico, Leonardo da Vinci e la prima grammatica italiana, Città di Castello, 1908.

3 Esta biblioteca fue adquirida en 1508 por el futuro papa León $\mathbf{X}$.

4 Sobre este texto, cf. Ciro Trabalza, Storia della grammatica italiana, Milano, 19o8, Apéndice. 
en valor científico y alteza de miras". En cambio, no podemos estar de acuerdo con Kukenheim cuando opina que "les rares observations sur la langue vulgaire qui au moyen âge se rencontrent par-ci par-là, ne méritent point le nom de règles de grammaire". Aunque en ellas no se incluya ningún capítulo de carácter fonético, las tres gramáticas provenzales analizan los problemas esenciales que plantean las ocho partes de la oración establecidas por la gramática latina. Además, en las Rasos se delimita la zona de lengua lemosina, se dice cuáles formas métricas son mejores en francés y cuáles en lemosín, y se censuran algunos de los errores cometidos por escritores de renombre. En las últimas páginas del Donatz se hace un breve estudio de la rima y se recoge una lista de palabras agrupadas de acuerdo con su terminación ${ }^{5}$.

En Inglaterra se redactaron varios tratados breves sobre ortografía y pronunciación francesa y, a veces, sobre algunas reglas gramaticales, con el fin de proporcionar la más indispensable instrucción sobre la lengua francesa a una nobleza que no quería dejar de hablar francés, cuando esta lengua iba siendo abandonada en favor de la inglesa. También se escribieron varios tratados de conversación y modelos de cartas, para uso de mercaderes o de personas que tuvieran intereses en Francia ${ }^{6}$. De todos estos escritos, el Donait francois de Jean Barton (140g) es el que posee más valor estrictamente gramatical. En él se proporcionan varias reglas de pronunciación, se estudian las ocho partes de la oración, se registra un buen número de verbos irregulares, de adverbios y de conjunciones, con sus correspondientes traducciones latinas?

5 Los textos del Donatz proensals y de las Rasos de trobar pueden verse en Françors Guessard, Grammaires provençales de Hugues Faidit et de Raymond Vidal de Besaudun, $2^{3}$ ed., Paris, 1858 , con una detallada introducción. Otra edición posterior de estos textos, falta de estudio preliminar pero hecha a la vista de todos los manuscritos entonces conocidos, es la de EDMUND STENGEL, Die beiden ältesten provenzalischen Grammatiken: "lo Donatz Proensals" und "las Rasos de Trobar" nebst einem provenzalisch-italienischen Glossar, Marburg, 1878. Existe traducción española, debida a Pedro Vignau Y Ballester, incluida en su libro la lengua de los trovadores. Estudios elementales sobre el lemosin provenzal, seguidos de una traducción de las "Rasos de trobar" y del "Donatz proensals", Madrid, 1865. E. LitTRé estudia el contenido del Donatz y de las Rasos en el capítulo 12 ("Grammaires romanes") de la obra Choix des poésies originales des troubadours, t. 2, Paris, 1817. También Paul MEYer ("Traités catalans de grammaire et de poétique", Ro, 6 , $\left.1877,341-35^{8} ; 8,181-210 ; 9,5^{\mathrm{I}-70}\right)$, recoge y analiza el texto de las Rasos según el manuscrito de la B.N.M. En el mismo trabajo estudia además las dos gramáticas inmediatamente posteriores a las Rasos: la Doctrina de cort de Terramagnino de Pisa y las Reglas de trobar de Jaufré de Foixa. El texto de Las flors del gay saber estier dichas las leys d'amors, de Guillaume Molinier, ha sido editado y traducido al francés moderno por M. GATIEN-ARNoult, Monuments de la littérature romane depuis le quatorzième siècle, Paris, 1841 .

6studian y comentan estas obras FERdinand Brunot, Histoire de la langue française des origines à 19oo, Paris, 1906, t. 1, pp. 374 s5.; Kathleen Lamblex, The teaching and cultivation of the French language in England during the Tudor and Stuart times, Manchester, 1920; ANNIE OWEN, "Le français en Angleterre du xiI ${ }^{\mathrm{e}}$ jusqu'au xve siècle", cap. 1 de la Introd. a Le traité de Walter de Bibbesworth sur la langue française, Paris, 1929; MILDRED POPE, "The Tractatus orthographiae of T.H. Parisii studentis", $M L R, 5$ (1910), 185-193.

${ }^{7}$ El texto completo del Donait puede verse, junto con otros estudios antiguos sobre el francés, en EDMund STENGEL, "Die ältesten Anleitungsschriften zur Erlernung der französischen Sprache", Zeitschrift für neufranzösische Sprache und Literatur, 1 $(1879), 1-4^{0}$. 
No obstante, Antonio de Nebrija fue el primero que escribió una gramática detallada y completa, concebida mucho más científicamente que las francesas, italianas o provenzales anteriores. Además, la suya es la primera gramática de una lengua nacional, ya que las obras provenzales describen sólo la modalidad regional del Sur de Francia, no la lengua que había de llegar a ser "nacional" y que entonces estaba en pleno desenvolvimiento y ya sobrepasaba con mucho su foco originario, la Iie de France. De igual manera, en las Regole se describe solamente la modalidad lingüistica de la ciudad de Florencia, y los estudios gramaticales escritos en Inglaterra, sobre ser muy fragmentarios, no representan la lengua francesa pura, sino más bien una mezcla de francés común y de anglonormando ${ }^{8}$.

\section{SU GLASIFICACIÓN DE LAS PARTES DE LA ORACIÓN}

El interés que surge durante el siglo xv por las lenguas vulgares del Occidente de Europa determina la aparición de numerosas gramáticas sobre ellas. Sus autores, al hacer la clasificación de las partes de la oración, se limitaban a adaptar a sus respectivas lenguas la clasificación de la gramática latina, como antes habían ya hecho los gramáticos romanos con respecto a la clasificación griega, de tal modo que las ocho partes establecidas por Dionisio de Tracia y transmitidas por los romanos, se aplicaron entonces al español, francés, italiano, alemán, etc. Y subsistió, por consiguiente, la caprichosa mezcla de criterios (semántico, morfológico, sintáctico) con que se había hecho la clasificación de las categorías oracionales ${ }^{9}$.

La importancia de la Gramática castellana de Antonio de Nebrija radica, no sólo en el hecho de ser la primera gramática española y de cualquier otra lengua románica o germánica, sino también en su original clasificación de las partes del discurso. Nebrija añade a las ocho partes tradicionales (nombre, pronombre, artículo, verbo, participio, preposición, adverbio y conjunción) dos nuevas categorías formales, el gerundio y el nombre participial infinito ${ }^{10}$. Al referirse por primera vez a

${ }^{8}$ No se conoce ninguna obra gramatical inglesa, alemana o portuguesa anterior a la obra de Nebrija. El primer estudio de este género que se hizo en Inglaterra fue la Bref Grammar de William Bullokar (1586). Cf. George LymanN KiTrredge, Some landmarks in the history of English grammars, Boston, 1906; Orro Funke, Die Frühzeit der englischen Grammatik, Bern, 1942, Pp. 25 ss. La Gramatica de linguagem portuguesa (1536) de Fernão de Oliveira fue la primera que se escribió en Portugal; cf. Josk Pereira Tavares, História da lingua portuguesa, Lisboa, 1923, pp. 72 ss. Cf. también Estanco Louro, Gramáticos portugueses do século xzi: $F$. de Oliveira, $J$. de Barros, P. de M. de Gândavo, D. N. de Leão, Lisboa, 193... (?). Las primeras gramáticas alemanas fueron Ias de Albert Oelinger y Laurentius Albertus (1573); cf. RUdolf von RaUmer, Geschichte der germanischen Philologie in Deutschland, Mün. chen, 1870 .

- Para el examen de estas definiciones, cf. B. Dexbrück, Vergleichende Syntax der indogermanischen Sprachen, Erster Teil, Strassburg, 1893, pp. 3 ss., y R. H. Robins, Ancient and mediaeval grammatical theory in Europe, London, 1951, pp. 41 ss.

1o "Nombre participial infinito" llama Nebrija al participio pasivo invariable de los tiempos compuestos con haber: he cantado, habia cantado, habré cantado. He, habia y habré son respectivamente el presente, el imperfecto ("passado no acabado") y el futuro ("venidero") del verbo haber; cantado es el nombre participial infinito. 
esta cuestión gramatical, advierte, en efecto, que es necesario añadir "el gerundio, el cual no tienen los griegos, i el nombre participial infinito, el cual no tienen los griegos ni latinos" (libro III, cap. 1). Pero este criterio formal no es, si bien se considera, el que de preferencia empleó Nebrija, según puede deducirse del siguiente cuadro, en el cual se advierte cómo Nebrija mezcla confusamente los distintos criterios de clasificación:

\begin{tabular}{|c|c|c|c|}
\hline & Forma & Significado & Función \\
\hline $\begin{array}{l}\text { nombre } \\
\text { (III, cap. 2) }\end{array}$ & $\begin{array}{l}\text { declinación } \\
\text { por caso }\end{array}$ & $\begin{array}{l}\text { persona } \\
\text { cosa }\end{array}$ & \\
\hline $\begin{array}{l}\text { pronombre } \\
\text { (III, cap. 8) }\end{array}$ & $\begin{array}{l}\text { declinación } \\
\text { por caso; } \\
\text { persona }\end{array}$ & nombre propio & \\
\hline $\begin{array}{l}\text { artículo } \\
\text { (III, cap. 9) }\end{array}$ & género & & $\begin{array}{l}\text { indicador de } \\
\text { género }\end{array}$ \\
\hline $\begin{array}{l}\text { verbo } \\
\text { (III, cap. 10) }\end{array}$ & $\begin{array}{l}\text { conjugación } \\
\text { por modos } \\
\text { y tiempos }\end{array}$ & & \\
\hline $\begin{array}{l}\text { gerundio } \\
\text { (III, cap. I2) }\end{array}$ & & $\begin{array}{l}\text { equivale a en } \\
+ \text { infinitivo } \\
\text { presente del } \\
\text { verbo del cual } \\
\text { deriva }\end{array}$ & \\
\hline $\begin{array}{l}\text { participio } \\
\text { (III, cap. 19) }\end{array}$ & & $\begin{array}{c}\text { acción y } \\
\text { pasión }\end{array}$ & \\
\hline $\begin{array}{l}\text { nombre parti- } \\
\text { cipial infinito } \\
\text { (III, cap. 14) }\end{array}$ & $\begin{array}{l}\text { semejante al } \\
\text { participio pa- } \\
\text { sivo; no tiene } \\
\text { tiempos, géne- } \\
\text { ro, número, ca- } \\
\text { so ni persona }\end{array}$ & $\begin{array}{l}\text { sustancia; ac- } \\
\text { ción, pero no } \\
\text { pasión }\end{array}$ & \\
\hline $\begin{array}{l}\text { preposición } \\
\text { (III, cap. 15) }\end{array}$ & & $\begin{array}{l}\text { delante de las } \\
\text { demás partes } \\
\text { de la oración, } \\
\text { yuxtapuesta o } \\
\text { en composi- } \\
\text { ción }\end{array}$ & \\
\hline $\begin{array}{l}\text { adverbio } \\
\text { (III, cap. 16) }\end{array}$ & & & $\begin{array}{c}\text { refuerza, debili- } \\
\text { ta o modifica el } \\
\text { significado del } \\
\text { verbo }\end{array}$ \\
\hline $\begin{array}{l}\text { conjunción } \\
\text { (III, cap. 17) }\end{array}$ & & & $\begin{array}{l}\text { relaciona las de- } \\
\text { más partes de } \\
\text { la oración }\end{array}$ \\
\hline
\end{tabular}


go $^{11}$. Así también, aunque en el cap. 1 dice que su razón para otorgar personalidad gramatical propia al nombre participial infinito es la falta de una forma análoga en griego y en latín, en el cap. 14 explica su decisión caracterizando morfológica y semánticamente esa nueva parte de la oración: el nombre participial infinito ostenta analogías y diferencias formales con el participio, difiere semánticamente de éste y comparte las significaciones del nombre y del verbo.

Así, pues, ni las definiciones que Nebrija ofrece de las ocho partes tradicionales de la oración, ni las de las dos nuevas categorías, nos permiten deducir cuál era el criterio de clasificación preferido por el gramático. Sin embargo en el cap. 9 del libro III, al señalar la función propia de los artículos, explica: "I ninguno se maraville que el la lo pusimos enel capitulo passado por pronombre, por que la diversidad delas partes dela oracion no esta sino enla diversidad dela manera de significar, como diziendo es mi amo, amo es nombre, mas diziendo amo a Dios, amo es verbo; e assi esta partezilla el la lo es para demostrar alguna cosa delas que arriba diximos, como diziendo Pedro lee $i$ el enseña, el es pronombre demostrativo o relativo; mas cuando añadimos esta partezilla a algun nombre para demostrar de que genero es, ia no es pronombre sino otra parte mui diversa dela oracion que llamamos articulo". También en el cap. 14 alude Nebrija a la manera de significar de las palabras, cuando termina su explicación del nombre participial infinito asegurando que "por esta causa pusimos esta parte dela oracion distinta delas otras, por la manera de significar que tiene mui distinta dellas".

Ya en el cap. 3 (sobre las distintas clases de nombres) había aludido Nebrija al triple valor oracional de una misma forma léxica, al afirmar - sin detenerse a explicar la causa- que un mismo vocablo, como mas, podía ser nombre, adverbio o conjunción: "esta partezilla mas, o es adverbio, como diziendo Pedro es mas blanco que Juan, o es conjunción, como diziendo io quiero mas tu no quieres, o es nombre comparativo, como diziendo io tengo mas que tu, quiero dezir mas mucho que tu".

De acuerdo con estas afirmaciones, podemos deducir que para Nebrija el modo de significar propio de cada palabra tenía especial importancia. Esta expresión, "manera de significar", la toma de las gramáticas escolásticas, dándole un nuevo y original significado, pero sin precisar ni siquiera cuáles eran los modos específicos de significación (como la permarten-

11 En su gramática latina, aunque mantiene la clasificación tradicional de las ocho partes de la oración, Nebrija expresa ya su deseo de considerar el gerundio como una categoría oracional independiente: "Hay algunos que cuentan los Gerundios con los verbos, porque rigen casos; algunos que con los nombres, porque tienen casos; algunos que dicen ser nombres participiales, porque en algunas cosas se semejan al nombre, en algunas al participio. Mas nosotros, por huir los argumentos, digamos que es otra parte dẹ la oración, mas que tiene mucha semejanza con el nombre; ni debe a ninguno esto parecer maravilla, pues que algunos pusieron más, y algunos menos que ocho partes de la oración" (Introducciones latinas, contrapuesto el romance al latin, Madrid, 1773 , p. 183). Nebrija no emplea ni podía emplear este razonamiento para definir al gerundio como parte separable de la oración española, porque si bien el gerundio español puede regir complementos directos al igual que el verbo, no conserva declinación casual alguna, ni analítica ni sintética. 
cia en el nombre o la fluctuación en el verbo) atribuidos por los gramáticos escolásticos a cada parte de la oración ${ }^{12}$.

Aunque Nebrija no lo declara explícitamente nunca, podemos suponer que su concepto de la "manera de significar" es doble, y abarca tanto el criterio estrictamente semántico cuanto el funcional. Al emplear dicha expresión, nunca trata de establecer una distinción clara entre el significado metafísico absoluto de una forma y su significado sintáctico ocasional. Las categorías que usa en sus ejemplos para mostrar la posibilidad de que una forma determinada tenga diversas maneras de significar son las que podían establecerse, no sólo de acuerdo con cualquier criterio formal, sino también de acuerdo con sus respectivos significados (nombre, verbo ${ }^{13}$, pronombre y nombre participial infinito) o con su diversa función (artículo, conjunción y adverbio).

La mayor originalidad de Nebrija en este punto radica, por consiguiente, no en su clasificación de las partes del discurso, sino de manera especial en su criterio de clasificación semántico-funcional, consecuencia de su original interpretación de las definiciones tradicionales de la escolástica.

University of California, Los Angeles.

JUDITH SENIOR

\section{DOS ROMANGES FRONTERIZOS EN LA TRADIGIÓN SEFARDÍ ORIENTAL}

En las colecciones de romances hasta ahora publicadas, casi no hay ejemplos de romances fronterizos procedentes de la tradición sefardí del Mediterráneo oriental. En cambio, se conocen bastantes romances de esa clase conservados en la tradición marroquí1. A la superioridad de esta última se refiere Menéndez Pidal cuando dice: "Ella conserva, a la vez que el arcaísmo distintivo de los judíos orientales, un mayor carácter histórico español que esos otros han perdido. Ciertos romances heroicos del Cid y de Bernardo, algunos fronterizos, varios moriscos, son frecuentes en Tánger, en Tetuán, en Alcazarquivir y en Larache, cuando

12 Cf. Charles Thurot, Notices et extraits de divers manuscrits latins pour servir à l'histoire des doctrines grammaticales au moyen âge, Paris, 1868, pp. 148 ss. X, en forma resumida, R. H. Robins, op. cit., pp. 81 ss.

${ }^{13}$ En la definición del verbo que da en su gramática española, Nebrija omite toda alusión a su significado. Sin embargo, en su gramática latina recoge la valoración semántica tradicional: el verbo expresa acción y pasión: “¿Qué cosa es verbo? Parte de la oración que se declina con modos y tiempos sin casos; y significación tiene de hacer y padecer" (p. 141).

1 Véanse las colecciones de $\mathrm{R}$. Menéndez Pidal, "Catálogo del romancero judíoespañol”, Cultura Española, 4 (1906), 1045-1077, y 5 (1907), 161-199 (reimpreso, con abreviación de algunos textos, en El Romancero, Teorias $e$ investigaciones, Madrid, 1928, y en Los romances de América, Buenos Aires-México, 1948); M. OrTegA, Los hebreos en Marruecos, Madrid, 1919; P. BÉNıchou, "Romances judeo-españoles de Marruecos", RFH, 6 (1944), 36-76, 105-138, 255-279, 313-381; y A. Larrea PALACín, Romances de Tetuán, 2 ts., Madrid, 1952. Recogen versiones marroquíes del Alcaide de Alhama (véase infra, nota 8), de Abenámar (Primavera y flor [abreviaremos en adelante "W."], $78 a$; Catálogo, núm. 10), del Romance de Portocarrero (Catálogo, núm. 11; Bénichou, núm. 62) y del de Garcilaso de la Vega (W., 93; 